\title{
Endothelial modulation of a nitric oxide donor complex-induced relaxation in normotensive and spontaneously hypertensive rats
}

\author{
Simone R. Potje ${ }^{\mathrm{a}}$, Jéssica A. Troiano ${ }^{\mathrm{a}}$, Marcella D. Grando ${ }^{\mathrm{b}}$, Murilo E. Graton ${ }^{\mathrm{a}}$, \\ Roberto S. da Silva ${ }^{\mathrm{b}}$, Lusiane M. Bendhack ${ }^{\mathrm{b}}$, Cristina Antoniali, \\ a Programa Multicêntrico de Pós-graduação em Ciências Fisiológicas - SBFis, São Paulo State University (UNESP), School of Dentistry, Araçatuba, Department of Basic \\ Sciences, Brazil \\ ${ }^{\mathbf{b}}$ University of São Paulo (USP), Faculty of Pharmaceutical Sciences of Ribeirão Preto, Department of Physics and Chemistry, Brazil
}

\section{A R T I C L E I N F O}

\section{Keywords:}

Nitric oxide donor

TERPY

eNOS

Mesenteric artery

SHR

\begin{abstract}
A B S T R A C T
We hypothesized that endothelium modulates relaxation induced by a nitric oxide (NO) donor ruthenium complex (TERPY, [Ru(terpy)(bdq)NO $]^{3+}$ ) in mesenteric arteries of normotensive and spontaneously hypertensive (SHR) rats in different ways. We analyzed the mechanism involved in TERPY-induced relaxation in the second and third branches of mesenteric arteries and investigated how endothelium contributes to the TERPY vasodilator effect on SHR blood vessels. TERPY induced concentration-dependent relaxation in endotheliumdenuded $\left(\mathrm{E}^{-}\right)$and endothelium-intact $\left(\mathrm{E}^{+}\right)$mesenteric arteries of normotensive rats and SHR. Pretreatment with ODQ (which inhibits soluble guanylyl cyclase) or TEA (tetraethylammonium, which blocks potassium channels) significantly reduced the TERPY vasodilator effect on $\mathrm{E}^{-}$mesenteric arteries of normotensive rats and SHR. The presence of endothelium shifted the concentration-effect curves for TERPY in $\mathrm{E}^{+}$mesenteric arteries of normotensive rats to the right. Conversely, the presence of endothelium shifted the concentration-effect curves for TERPY in the case of SHR $\mathrm{E}^{+}$mesenteric arteries to the left, which suggested increased potency. L-NNA, a more selective endothelial NO synthase (eNOS) inhibitor, reduced TERPY potency in SHR. The presence of endothelium and notably of NOS contributed to the TERPY vasodilator action in SHR: TERPY promoted eNOS Ser ${ }^{1177}$ phosphorylation with consequent NO production and increased soluble guanylyl cyclase activity, which may have directly activated potassium channels.
\end{abstract}

\section{Introduction}

Nitric oxide (NO) plays an important role in hemodynamic regulation and vascular tone control in the cardiovascular system [1]. Compounds that can release or donate NO might mimic endogenous NO activity, especially in hypertension, where endogenous NO production is impaired [2] and/or enhanced reactive oxygen species (ROS) can inactivate or sequester NO [3]. Two NO donors, sodium nitroprusside (SNP) and nitroglycerin (TNG), are currently employed in the clinical setting. SNP is prescribed to patients with acute pulmonary edema or severe left ventricular dysfunction [4], whereas TNG is used to treat angina pectoris [5] and acute heart episodes [6]. However, both vasodilators have limitations. The SNP hypotensive effect can lead to reflex tachycardia $[7,8]$, and the cyanide molecules released during biological SNP degradation are related to severe toxicity [9]. On the other hand, chronic TNG use induces tolerance [10]. To avoid the clinical side effects of these NO donors, many macrocyclic nitrosyl ruthenium complexes that can act as NO donors have been synthesized and studied. Three ruthenium complexes, namely trans-[RuCl([15] aneN $\left._{4}\right) \mathrm{NO}^{2+}$ (15-ANE), cis-[RuCl(bpy $\left.)_{2}(\mathrm{py}) \mathrm{NO}_{2}\right]\left(\mathrm{PF}_{6}(6)\right)(\mathrm{RuBPY})$, and $\left[\mathrm{Ru}(\text { terpy)(bdq)NO }]^{3+}\right.$ (TERPY), have been shown to exert hypotensive and vasodilator actions on different experimental models of hypertension [8,11-15]. Comparison of these complexes has revealed that TERPY promotes the most powerful intracellular calcium concentration

\footnotetext{
Abbreviations: NO, nitric oxide; SNP, sodium nitroprusside; TNG, nitroglycerine; SHR, spontaneously hypertensive rats; TERPY, [Ru(terpy)(bdq)NO ${ }^{3+} ; \mathrm{E}^{-}$, endothelium-denuded; $\mathrm{E}^{+}$,

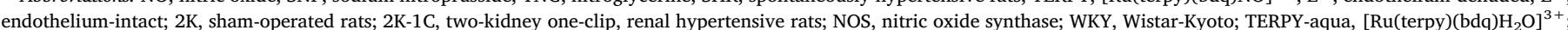

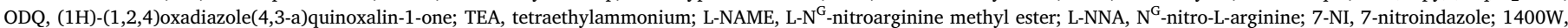

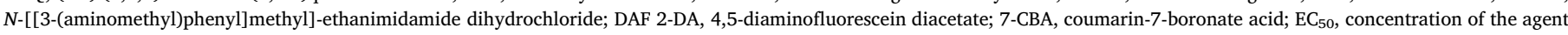

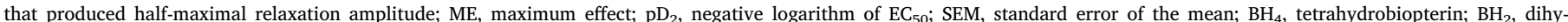

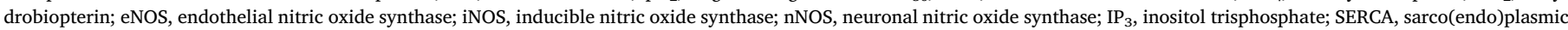
$\mathrm{Ca}^{2+}$-ATPase; sGC, soluble guanylate cyclase; cGMP, cyclic guanosine monophosphate; ROS, reactive oxygen species; COX, cyclooxygenase

* Corresponding author at: Faculdade de Odontologia de Araçatuba - UNESP/ Departamento de Ciências Básicas, Rua: José Bonifácio 1193 - CEP: 16015-050, Araçatuba, SP, Brazil.

E-mail address: crisant@foa.unesp.br (C. Antoniali).
} 
drop in vascular smooth muscle cells [16], which suggests that it displays the best vasodilator effect.

Previous studies have demonstrated that TERPY induces a slow and long-lasting hypotensive action without reflex tachycardia in normotensive and spontaneously hypertensive rats (SHR) $[8,17]$. In addition, TERPY displays a vasodilator effect on different blood vessels, with the exception of the basilar arteries of normotensive rats [18]. This is an important feature of TERPY because it avoids cerebral vasodilation and consequent headache [19]. Another advantage of TERPY is its lack of cytotoxicity [18].

TERPY induces similar vasodilator effects on endothelium-denuded $\left(\mathrm{E}^{-}\right)$mesenteric artery rings of sham-operated $(2 \mathrm{~K})$ and renal hypertensive (2K-1C) rats [20] and also on $\mathrm{E}^{-}$aortic rings of normotensive rats and SHR [8]. Nevertheless, endothelium modulates the TERPY vasodilator action in normotensive rats and SHR in different ways. Endothelium impairs the TERPY vasodilator effect on normotensive rat aortas $[14,15]$. In contrast, the TERPY vasodilator action is improved in SHR endothelium-intact $\left(\mathrm{E}^{+}\right)$aortas as compared to SHR $\mathrm{E}^{-}$aortas. Moreover, despite the endothelial dysfunction observed in SHR aortas, a non-selective NO synthase (NOS) inhibitor shifts TERPY-induced relaxation curves to the right, which suggests that NOS activity in SHR aortas improves the TERPY effect [15].

Resistance vessels are closely associated with blood flow and capillary pressure regulation [21]. SHR peripheral resistance arteries show endothelial dysfunction and vascular remodeling, which are deeply related to high blood pressure levels [22-24]. Despite the aforementioned observations, a higher TERPY hypotensive action is verified in SHR as compared to normotensive rats. Analysis of the mechanisms involved in the TERPY vasodilator effect on SHR peripheral resistance arteries could explain this fact. We started this study by hypothesizing that endothelium modulates TERPY-induced relaxation in mesenteric arteries of normotensive rats and SHR differently. This study aimed to analyze the mechanisms underlying the TERPY effect on the second and third branches of such mesenteric arteries and to evaluate how endothelium contributes to the TERPY vasodilator effect on SHR mesenteric arteries.

\section{Material and methods}

All the experiments complied with the U.K. Animal guidelines (Guide for the care and use of laboratory animals) and were approved by the Ethics Committee on Animal Use (CEUA) of the School of Dentistry of Araçatuba (UNESP, process number 00440/2013).

\subsection{Animals}

This study employed male SHR aged 120 days, weighing approximately $300 \mathrm{~g}$, and with systolic blood pressure $\geq 150 \mathrm{~mm} \mathrm{Hg}$. Agematched normotensive Wistar rats weighing approximately $400 \mathrm{~g}$ and with systolic blood pressure $\leq 110 \mathrm{~mm} \mathrm{Hg}$ were used as controls (Fig. S1). Systolic blood pressure was evaluated by tail plethysmography (PowerLab, ADInstruments, Melbourne - Australia). Animals were housed under standard laboratory conditions and $12 \mathrm{~h}$ light/dark cycles, at $22^{\circ} \mathrm{C}$, with free access to food and water.

Wistar-Kyoto (WKY) rats were not used as controls because this strain bears a hypertension gene and is prone to genetic variability [25,26]. Furthermore, like SHR, WKY rats display cardiomyocyte hypertrophy and left ventricular diastolic stiffness and can therefore develop spontaneous hypertension $[25,26]$. On the other hand, Wistar rats do not have altered cardiomyocytes or altered left ventricle [27] and are surely normotensive, with blood pressure $\leq 110 \mathrm{~mm} \mathrm{Hg}$ (Fig. S1).

\subsection{Vessel preparation}

Wistar (designated normotensive hereafter) rats and SHR were submitted to inhalation of halothane (Tanohalo $^{\circledR}$, Cristália, Itapira,
Brazil), decapitated, and exsanguinated. Mesenteric artery beds were removed and placed in Petri dishes containing cold Krebs-Henseleit solution with the following composition (mM): $\mathrm{NaCl} 130.00, \mathrm{NaHCO}_{3}$ 14.9, $\mathrm{C}_{6} \mathrm{H}_{12} \mathrm{O}_{6} 5.5, \mathrm{KCl}$ 4.7, $\mathrm{KH}_{2} \mathrm{PO}_{4} 1.18, \mathrm{MgSO}_{4}$ 1.17, and $\mathrm{CaCl}_{2}$ 1.6; $\mathrm{pH}$ 7.4. Mesenteric arteries were cleaned of connective tissue with the aid of a stereomicroscope (Luxeo 2S, Labomed, Los Angeles, CA - USA).

\subsection{Vascular reactivity}

The second or the third branch of mesenteric arteries (internal diameter $=200-300 \mu \mathrm{m}$ ) was cut into 2-mm-long rings. To measure isometric tension, these rings were mounted in a small vessel four chambers myograph (DMT, AD Instruments, Melbourne - Australia). More specifically, two tungsten wires (diameter $=40 \mu \mathrm{m}$ ) were introduced through a ring, which was mounted according to the method described by Mulvany and Halpern [23]. For some rings, endothelium was maintained $\left(\mathrm{E}^{+}\right)$, whereas for other rings, endothelium was removed $\left(\mathrm{E}^{-}\right)$by gently rubbing the intimal surface with a human hair. After 10-min equilibration in oxygenated Krebs-Henseleit solution gassed with $95 \% \mathrm{O}_{2}$ and $5 \% \mathrm{CO}_{2}$ at $37{ }^{\circ} \mathrm{C}$ and $\mathrm{pH} 7.4$, rings were stretched to their optimal lumen diameter, to develop active tension, and they were normalized to a $100-\mathrm{mm} \mathrm{Hg}$ transmural pressure [24]. Subsequently, rings were left under basal resting tension for $30 \mathrm{~min}$. To test preparation viability, rings were stimulated with a solution containing high potassium concentration ( $\mathrm{KCl} 120 \mathrm{mM}$ ) for $10 \mathrm{~min}$. Endothelial cell integrity was confirmed by over $60 \%$ and $80 \%$ relaxation in arteries of SHR and normotensive rats in response to acetylcholine $1 \mu \mathrm{M}$, respectively. Efficient endothelial cell removal was confirmed by lack of relaxation in rings pre-contracted with phenylephrine $1 \mu \mathrm{M}$.

\subsection{Protocols}

Cumulative concentration-response curves (from $10 \mathrm{nM}$ to $100 \mu \mathrm{M}$ ) were constructed for the effect of the NO donor TERPY on mesenteric artery rings of normotensive rats and SHR. $\mathrm{E}^{-}$rings were contracted with phenylephrine $1 \mu \mathrm{M}$, whereas $\mathrm{E}^{+}$rings were contracted with phenylephrine $10 \mu \mathrm{M}$. To evaluate the cellular pathways involved in this resistance vessel relaxation in normotensive rats and SHR, concentration-response curves were constructed for TERPY after 30-min incubation in the absence or in the presence of (1) the selective soluble guanylyl cyclase inhibitor (1H)-(1,2,4)oxadiazole(4,3-a)quinoxalin-1one (ODQ, $1 \mu \mathrm{M}$ ); (2) the non-selective potassium channel blocker tetraethylammonium (TEA, $1 \mathrm{mM}$ ); (3) the non-selective cyclooxygenase-1 and cyclooxygenase-2 (COX) inhibitor indomethacin $(10 \mu \mathrm{M})$; and (4) the non-selective NOS inhibitor $\mathrm{L}-\mathrm{N}^{\mathrm{G}}$-Nitroarginine methyl ester (LNAME, $100 \mu \mathrm{M}$ ). For SHR vessels, the effect of the following inhibitors were also evaluated: (5) the more selective endothelial NOS (eNOS) inhibitor $\mathrm{N}^{\mathrm{G}}$-Nitro-L-arginine (L-NNA, $100 \mu \mathrm{M}$ ); (6) the more selective neuronal NOS (nNOS) inhibitor 7-nitroindazole (7-NI, $100 \mu \mathrm{M})$; and (7) the selective inducible NOS (iNOS) inhibitor N-([3-(aminomethyl) phenyl]methyl) ethanimidamide dihydrochloride (1400W, $10 \mu \mathrm{M})$. The concentrations of the drugs used during the vascular reactivity experiments agreed with the concentrations employed during previous studies by Bonaventura et al. [28] and Araújo et al. [20]. For some $\mathrm{E}^{-}$mesenteric artery rings, cumulative concentration-response curves (from $10 \mathrm{nM}$ to $100 \mu \mathrm{M})$ to TERPY-aqua ([Ru(terpy)(bdq) $\left.\mathrm{H}_{2} \mathrm{O}\right]^{3+}$ ), without NO molecule, were constructed to prove that TERPY-induced relaxation is NO-dependent in blood vessels of normotensive rats and SHR.

\subsection{Flow cytometry}

The superior branch of SHR mesenteric artery beds was isolated, cleaned, and opened longitudinally. By using a suitable plastic scraper, endothelial cells were mechanically removed from the vessels in a plate containing Hanks solution with the following composition (mM): $\mathrm{CaCl}_{2}$ 1.6, $\mathrm{MgCl}_{2}$ 1.0, $\mathrm{NaCl} 120.0$, KCI 5.0, $\mathrm{NaH}_{2} \mathrm{PO}_{4}$ 0.5, $\mathrm{C}_{6} \mathrm{H}_{12} \mathrm{O}_{6}$ 10.0, and 
HEPES 10.0; pH 7.4. The endothelial cell suspension was centrifuged (Centrifuge 5810R, Eppendorf, Hamburg, Germany) at $1000 \mathrm{rpm}$ and room temperature for $5 \mathrm{~min}$. Endothelial cells were characterized by cellular size and complexity. Absolute minimum thresholds of 180 and 160 were set at the SSC-A (Side SCatter) and FSC-A (Forward SCatter), respectively, to exclude the instrument noise threshold. Samples running on the Attune instrument (Attun ${ }^{\mathrm{TM}}$ Acoustic Focusing Cytometer, Applied Biosystems, Vic, Australia) were analyzed at high sensitivity and at a maximum acquisition rate of 50 events/s for $60 \mathrm{~s}$, so a total of 2500 endothelial cells or events/rat were analyzed by flow cytometry. Cells were not incubated (Blank) or they were incubated (Basal) for 20 min with the fluorescent dye 4,5-diaminofluorescein diacetate (DAF2DA, $10 \mu \mathrm{M})$, a fluorophore that reacts with intracellular NO. Subsequently, cells were stimulated with TERPY $(10 \mu \mathrm{M})$ for $10 \mathrm{~min}$, in the absence or in the presence of L-NAME $(100 \mu \mathrm{M})$, L-NNA $(100 \mu \mathrm{M})$, 7-NI $(100 \mu \mathrm{M}), 1400 \mathrm{~W}(10 \mu \mathrm{M})$, or indomethacin $(0.1 \mu \mathrm{M})$. Fluorescence emission at $530 / 30 \mathrm{~nm}$ was measured with a $488-\mathrm{nm}$ blue laser (50 mW, Life Technologies Applied Biosystems, Vic, Australia). For cytofluorographic analysis, acquisition was set at 2500 endothelial cells/rat; the mean fluorescence intensity was measured in all the samples. The mean fluorescence intensity variation was calculated by the ratio between the number of cells loaded with DAF-2DA (Basal) and the number of cells loaded with DAF-2DA and stimulated with one of the drugs cited above. This methodology was described by Bonaventura et al. [14] and Cunha et al. [29].

\subsection{Western blot}

Mesenteric artery beds were removed from the rats, cleaned, frozen in liquid nitrogen, and stored at $-80^{\circ} \mathrm{C}$. Samples were macerated in liquid nitrogen and separately homogenized in RIPA buffer (supplemented with a cocktail of protease and phosphatase inhibitors) with the aid of a sonicator (Vibra Cell Sonics, Newtown, USA). Homogenates were centrifuged $\left(4^{\circ} \mathrm{C}, 10000 \mathrm{rpm}\right.$, for $20 \mathrm{~min}$ ), and supernatants were collected for protein determination [30]. Ten micrograms $(10 \mu \mathrm{g})$ of total protein from a certain supernatant was submitted to electrophoresis in $8-10 \%$ polyacrylamide gel and transferred to a nitrocellulose membrane. Then, the membrane was incubated at $4{ }^{\circ} \mathrm{C}$, overnight, with primary antibodies against sGC $\alpha$ (1:500, Santa Cruz Biotechnology, SC-376502); sGC $\beta$ (1:500, Santa Cruz Biotechnology, SC-20955); $\mathrm{K}_{\mathrm{V} 1.5}$ (1:5000, Millipore, AB5182); maxiK (1:5000, BD Biosciences, 611248); SK3 (1:5000, Santa Cruz Biotechnology, SC28621); SUR2B (1:1000, Santa Cruz Biotechnology, SC-5793); Kir 6.1 (1:1000, Santa Cruz Biotechnology, SC-11224) and eNOS (1:1000, Santa Cruz Biotechnology, SC-654) for homogenates from normotensive rats and SHR. Some mesenteric artery beds were treated with TERPY $(1 \mu \mathrm{M}, 30 \mathrm{~min})$ or not (control). Ten micrograms $(10 \mu \mathrm{g})$ from these samples, in a nitrocellulose membrane, were incubated at $4{ }^{\circ} \mathrm{C}$, overnight, with primary antibodies against p-eNOS $\operatorname{Ser}^{1177}$ (1:1000, Millipore, 07-428) and p-eNOS $\mathrm{Thr}^{495}$ (1:1000, BD Bioscience, 612707). Next, the membrane was incubated with secondary antibody anti-rabbit (1:1000) or anti-mouse $(1: 1000)$ at room temperature for $60 \mathrm{~min}$. A chemiluminescent substrate that had been exposed to a radiographic film was used to detect the bands. $\beta$-Actin (1:12000, Sigma-Aldrich, A5441) was used to normalize the results. Band intensity was quantified with the optical densitometry software ImageJ.

\subsection{Colorimetric Griess reaction}

We used the second or the third branch of the mesenteric arteries of normotensive rats and SHR. In the bath chamber, we incubated all the samples at $37^{\circ} \mathrm{C}$ without (non-treatment) or with TERPY $(1 \mu \mathrm{M}$, $30 \mathrm{~min}$ ). Then, $50 \mu \mathrm{L}$ of the bath solution from all samples were collected and added to $50 \mu \mathrm{L}$ of Griess reagent (a 1:1 dilution of $1 \% \mathrm{~N}-(1$ Naphthyl)ethylenediamine dihydrochloride in distilled water and $1 \%$ sulphanilamide in $5 \%$ phosphoric acid) using a 96 well plate. We set up sodium nitrite doubling dilutions for a standard curve starting with $200 \mu \mathrm{M}$ nitrite. The absorbance was read at $540 \mathrm{~nm}$.

\subsection{Measurement of $\mathrm{ONOO}^{-}$production by coumarin-7-boronate acid (7- $C B A)$}

In the bath chamber, the second or the third branch of mesenteric arteries of normotensive rats and SHR were incubated at $37^{\circ} \mathrm{C}$ without (non-treatment) or with TERPY $(1 \mu \mathrm{M}, 30 \mathrm{~min})$. Then, $50 \mu \mathrm{L}$ of the bath solution from all samples were collected and added to $50 \mu \mathrm{L}$ of $20 \mu \mathrm{M} 7$ CBA diluted in PBS for $30 \mathrm{~min}$. This mixture was placed in 96-well assay plates, and fluorescence analysis of the oxidation product 7-OH-coumarin $(\mathrm{COH})$ [31] was performed on a SpectraMax M5 Microplate Reader (Molecular Advices, Sunnyvale, CA). Fluorescence was measured at $332 \mathrm{~nm}$ (excitation) and $447 \mathrm{~nm}$ (emission). The results were normalized to total cellular protein.

\subsection{Drugs}

The NO donor TERPY (MW: 951.00) and TERPY-aqua (MW: 746.39) were synthesized [32] in the Analytical Chemistry Laboratory of the Department of Physics and Chemistry of the Faculty of Pharmaceutical Sciences of Ribeirão Preto - USP; TERPY structure was demonstrated by Bonaventura et al. [14] and Munhoz et al. [8]. Phenylephrine (L-phenylephrine hydrochloride); acetylcholine (acetylcholine chloride); ODQ ((1H)-(1,2,4)oxadiazole(4,3-a)quinoxalin-1-one); TEA (tetraethylammonium); L-NAME ( $\mathrm{N}^{\mathrm{G}}$-nitro-L-arginine methyl ester hydrochloride); L-NNA ( $\mathrm{N}^{\mathrm{G}}$-nitro-L-arginine); 7-NI (7-nitroindazole); 1400W (N([3-(aminomethyl)phenyl]methyl)ethanimidamide dihydrochloride); DAF-2DA (4,5-diaminofluoresceine diacetate); dimethylsulfoxide; and indomethacin were obtained from Sigma-Aldrich (St. Louis, Missouri- USA). Phenylephrine, acetylcholine, L-NAME, ODQ, and TEA were dissolved in deionized water. L-NNA, 7-NI, 1400W, and DAF2-DA were dissolved in dimethylsulfoxide. Indomethacin was dissolved in ethanol. The final dimethylsulfoxide or ethanol concentration in the bath solution did not exceed $0.1 \%$.

\subsection{Statistical analysis}

For functional studies, $\mathrm{EC}_{50}$ (concentration of the agent that produced half-maximal relaxation amplitude) values were determined after logarithmic transformation of normalized concentration-response curves and are reported as the negative logarithm $\left(\mathrm{pD}_{2}\right)$. Maximum effect (ME) values were represented as percentage and were considered as the maximal amplitude response reached in the concentration-effect curves for the relaxation agent. Results are expressed as the mean \pm standard error of the mean (SEM) of obtained values; $n$ indicates the number of animals, the number of mesenteric artery rings, or the number of mesenteric artery beds that were used. Results were analyzed and compared between groups by using one-way ANOVA with Tukey post-hoc test. Statistical analysis was performed with the software Prism GraphPad 5.0. Differences were considered statistically significant when $p<0.05$.

\section{Results}

\subsection{TERPY-induced relaxation is similar in $E^{-}$mesenteric arteries of normotensive rats and $S H R$}

TERPY induced a concentration-dependent vasodilator effect on $\mathrm{E}^{-}$ mesenteric artery rings of normotensive rats (ME: $100.7 \pm 4.2 \%, \mathrm{pD}_{2}$ : $5.33 \pm 0.06, \mathrm{n}=4)$ and SHR (ME: $100.9 \pm 2.3 \%, \mathrm{pD}_{2}: 5.29 \pm 0.19$, $\mathrm{n}=6$ ) (Fig. 1). TERPY without NO ligand; i.e., TERPY-aqua ([Ru(terpy) (bdq) $\left.\mathrm{H}_{2} \mathrm{O}\right]^{3+}$ ), did not promote relaxation in $\mathrm{E}^{-}$mesenteric artery rings of normotensive rats (ME: $8.3 \pm 2.1 \%, \mathrm{n}=5$ ) and SHR (ME: $11.6 \pm 5.2 \%, \mathrm{n}=5$ ), which suggests that NO activates the 


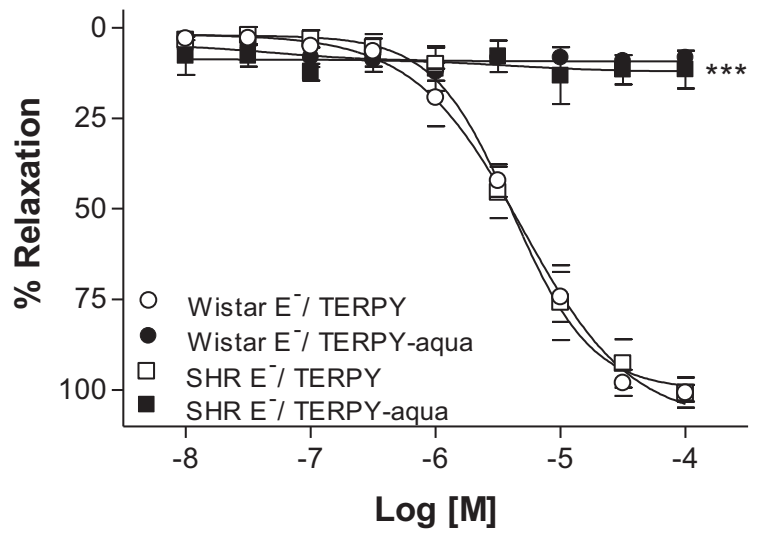

Fig. 1. TERPY $(10 \mathrm{nM}-100 \mu \mathrm{M})$ or TERPY-aqua $(10 \mathrm{nM}-100 \mu \mathrm{M})$ relaxation effect on the $\mathrm{E}^{-}$mesenteric resistance arteries of normotensive Wistar rats (TERPY, white circle, $n=4$; TERPY-aqua, black circle, $n=5$ ) and SHR (TERPY, white square, $n=6$; TERPY-aqua, black square, $n=5$ ). Data are reported as the mean \pm S.E.M. ${ }^{* * *} p<0.001$ denotes differences between TERPY-aqua and TERPY effects (One-Way ANOVA, followed by Tukey test).

mechanisms involved in smooth muscle cell relaxation.

3.2. TERPY-induced relaxation in $E^{-}$mesenteric arteries of normotensive rats and SHR involves soluble guanylyl cyclase (sGC) and potassium channel activation

On the basis of Fig. 2A and B, ODQ (a selective sGC inhibitor) reduced the maximum relaxation induced by TERPY in $\mathrm{E}^{-}$mesenteric artery rings of normotensive rats (ME: $39.4 \pm 5.6 \%, n=5$ ) and SHR (ME: $30.5 \pm 2.5 \%, \mathrm{n}=5$ ), but ODQ did not abolish the TERPY effect. TEA (a non-selective potassium channel blocker) reduced TERPY potency as shown by the $\mathrm{pD}_{2}$ values in $\mathrm{E}^{-}$mesenteric artery rings of normotensive rats $\left(\mathrm{pD}_{2}: 4.67 \pm 0.42, \mathrm{n}=6\right)$ and $\mathrm{SHR}\left(\mathrm{pD}_{2}\right.$ : $4.72 \pm 0.23, \mathrm{n}=5$ ) and by the maximum relaxation induced by TERPY in $\mathrm{E}^{-}$mesenteric artery rings of normotensive rats (ME: $64.8 \pm 3.3 \%, \mathrm{n}=6$ ) and SHR (ME: $70.0 \pm 4.5 \%, \mathrm{n}=5$ ) (Fig. $2 \mathrm{C}$ and D). However, according to Fig. $2 \mathrm{E}$ and F, incubation with ODQ plus TEA almost abolished TERPY-induced relaxation in $\mathrm{E}^{-}$mesenteric arteries of normotensive rats (ME: $9.9 \pm 0.8 \%, \mathrm{n}=5$ ) and SHR (ME: $9.0 \pm 1.4 \%, \mathrm{n}=5$ ).

\subsection{Protein expression of $s G C$ subunits and potassium channels in} mesenteric arteries of normotensive rats and SHR

Mesenteric artery beds of normotensive rats and SHR had similar expression of sGC $\alpha$ and $\beta$ subunits. Mesenteric artery beds of normotensive rats and SHR did not differ in terms of protein expression of the voltage-dependent potassium channel $\left(\mathrm{K}_{\mathrm{V}}\right) \mathrm{K}_{\mathrm{V} 1.5}$ subunit; these beds did not differ in terms of protein expression of both ATP-sensitive potassium channel ( $\mathrm{K}_{\mathrm{ATP}}$ ) subunits (SUR2B and Kir 6.1), either. Nevertheless, protein expression of the small conductance calcium-activated potassium channel (SK3) and of the big conductance calciumactivated potassium channel (maxiK) decreased in SHR mesenteric artery beds as compared to mesenteric artery beds of normotensive rats (Fig. 3).

\subsection{Endothelium increases TERPY potency in SHR mesenteric resistance arteries}

TERPY induced a concentration-dependent vasodilator effect in $\mathrm{E}^{+}$ mesenteric artery rings of normotensive rats and SHR (Fig. 4). TERPY induced similar maximum effects in $\mathrm{E}^{+}$and $\mathrm{E}^{-}$mesenteric arteries of normotensive rats $\left(\mathrm{E}^{+} \mathrm{ME}: 96.9 \pm 3.2 \%, \mathrm{n}=4 ; \mathrm{E}^{-} \quad \mathrm{ME}\right.$ :
$100.7 \pm 4.2 \%, \mathrm{n}=4)$ and SHR ( $\mathrm{E}^{+} \mathrm{ME}: 103.1 \pm 2.4 \%, \mathrm{n}=5 ; \mathrm{E}^{-}$ ME: $100.9 \pm 2.3 \%, \mathrm{n}=6$ ) (Fig. $4 \mathrm{~A}$ and $\mathrm{B}$ ). However, TERPY potency was higher in SHR $\mathrm{E}^{+}$mesenteric artery rings than in SHR $\mathrm{E}^{-}$mesenteric artery rings $\left(\mathrm{E}^{+} \mathrm{pD}_{2}: 6.01 \pm 0.05, \mathrm{n}=5 ; \mathrm{E}^{-} \quad \mathrm{pD}_{2}\right.$ : $5.29 \pm 0.19, \mathrm{n}=6$ ) (Fig. 4A). On the other hand, endothelium impaired the TERPY potency in mesenteric arteries of normotensive rats $\left(\mathrm{E}^{+} \mathrm{pD}_{2}: 4.73 \pm 0.07, \mathrm{n}=4 ; \mathrm{E}^{-} \mathrm{pD}_{2}: 5.33 \pm 0.06, \mathrm{n}=4\right.$ ) (Fig. $4 \mathrm{~B}$ ).

\subsection{The NOS enzyme improves TERPY-induced relaxation in SHR} mesenteric arteries, but not in mesenteric arteries of normotensive rats

L-NAME (a non-selective NOS inhibitor) reduced TERPY potency $\left(\mathrm{pD}_{2}: 5.03 \pm 0.10, \mathrm{n}=4\right)$ but it did not change the maximum effect (ME: $97.4 \pm 0.9 \%, n=4$ ) in the case of SHR $\mathrm{E}^{+}$mesenteric artery rings (Fig. 4C). On the other hand, L-NAME increased TERPY potency in $\mathrm{E}^{+}$mesenteric rings of normotensive rats $\left(\mathrm{pD}_{2}: 5.31 \pm 0.10, \mathrm{n}=4\right)$ without modifying the maximum effect (ME: $96.4 \pm 1.8 \%, n=4$ ) (Fig. 4D).

3.6. The cyclooxygenase pathway does not participate in TERPY-induced relaxation in $E^{+}$mesenteric arteries of normotensive rats and $S H R$

TERPY potency and the maximum vasodilator effect induced by TERPY in $\mathrm{E}^{+}$resistance artery rings of normotensive rats $\left(\mathrm{pD}_{2}\right.$ : $4.70 \pm 0.08, \mathrm{n}=4 ;$ ME: $94.6 \pm 1.1 \%, \mathrm{n}=4)$ and SHR $\left(\mathrm{pD}_{2}\right.$ : $5.97 \pm 0.07, \mathrm{n}=4$; ME: $95.0 \pm 2.3 \%, \mathrm{n}=4$ ) incubated with indomethacin, a non-selective COX inhibitor, did not change as compared to the corresponding $\mathrm{E}^{+}$rings (Fig. $4 \mathrm{E}$ and F).

\subsection{The eNOS, but not the iNOS or the nNOS, enzyme participates in TERPY-induced relaxation}

We tested three different inhibitors to identify which NOS isoform was involved in the TERPY effect observed in SHR. L-NNA (a more selective eNOS inhibitor) decreased TERPY potency $\left(\mathrm{pD}_{2:} 4.96 \pm 0.20\right.$, $\mathrm{n}=4$ ) but not the TERPY maximum effect (ME: $96.1 \pm 1.0 \%, \mathrm{n}=4$ ) (Fig. 5A). 1400W (a selective iNOS inhibitor) $\left(\mathrm{pD}_{2}: 6.11 \pm 0.17\right.$, $\mathrm{n}=4$; ME: $94.4 \pm 2.8 \%, \mathrm{n}=4$ ) and 7-NI (a more selective nNOS inhibitor) ( $\mathrm{pD}_{2}: 6.05 \pm 0.07, \mathrm{n}=4$; ME: $94.6 \pm 1.9 \%, \mathrm{n}=4$ ) did not change TERPY potency or maximum effect (Fig. $5 \mathrm{~B}$ and C) in SHR $\mathrm{E}^{+}$ mesenteric arteries.

\subsection{TERPY increases NO in SHR superior mesenteric artery endothelial cells through a L-NNA-sensitive mechanism}

The presence of L-NAME abolished the DAF-2DA basal fluorescence intensity (2979.40 $\pm 191.03, \mathrm{n}=5$, in arbitrary units) in SHR superior mesenteric artery endothelial cells (Fig. 6, $148.20 \pm 325.08, n=5$ ). Stimulation with TERPY increased DAF-2DA fluorescence intensity $(6528.80 \pm 145.66, \mathrm{n}=5)$, and these results remained unaltered after incubation with 7-NI $(6724.80 \pm 120.63, \mathrm{n}=4), \quad 1400 \mathrm{~W}$ $(6606.60 \pm 144.32, \mathrm{n}=5)$, or indomethacin $(6560.40 \pm 92.51$, $\mathrm{n}=5$ ). Nevertheless, incubation of endothelial cells with L-NAME $(4470.40 \pm 224.90, \mathrm{n}=5)$ or L-NNA (4498.05 $\pm 77.89, \mathrm{n}=4)$ prior to stimulation with TERPY decreased DAF-2DA fluorescence intensity as compared to values obtained for endothelial cells stimulated with TERPY only, but fluorescence intensity was not abolished like it was diminished in the presence of L-NAME only (Fig. 6).

\subsection{TERPY increases eNOS phosphorylation at the threonine ${ }^{495}\left(\mathrm{Thr}^{495}\right)$ residue in mesenteric arteries of normotensive rats and the serine ${ }^{1177}$ $\left(\mathrm{Ser}^{1177}\right)$ residue in SHR mesenteric arteries}

Stimulation of normotensive rats mesenteric arteries with TERPY $(1 \mu \mathrm{M})$ increased eNOS phosphorylation at $\operatorname{Thr}^{495}(0.44 \pm 0.07, \mathrm{n}=4$, in arbitrary units) as compared to non-stimulated mesenteric arteries 
A)

Wistar

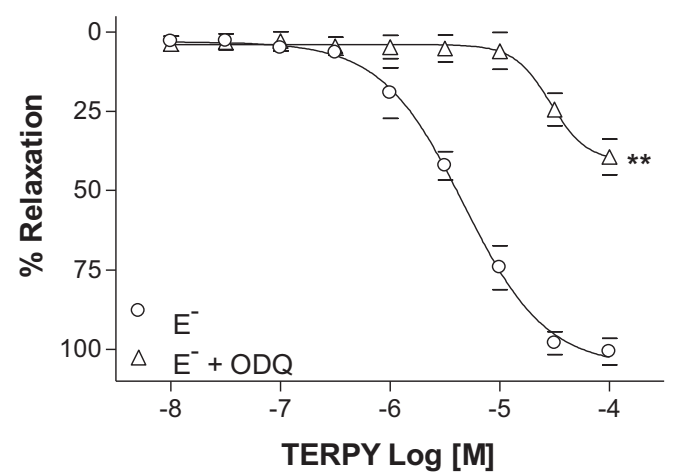

C)



E)

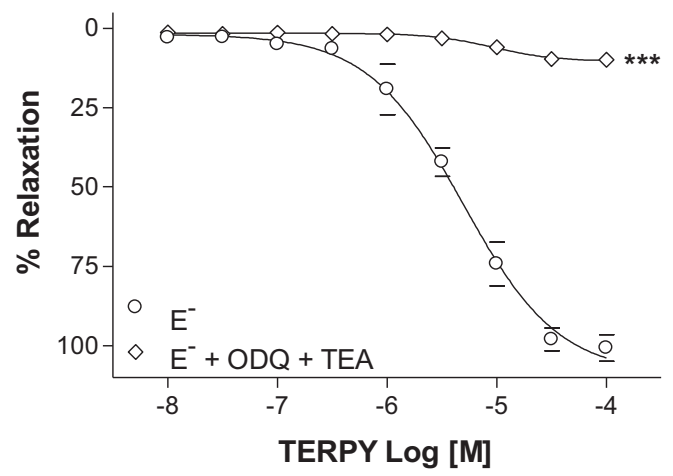

B)

SHR

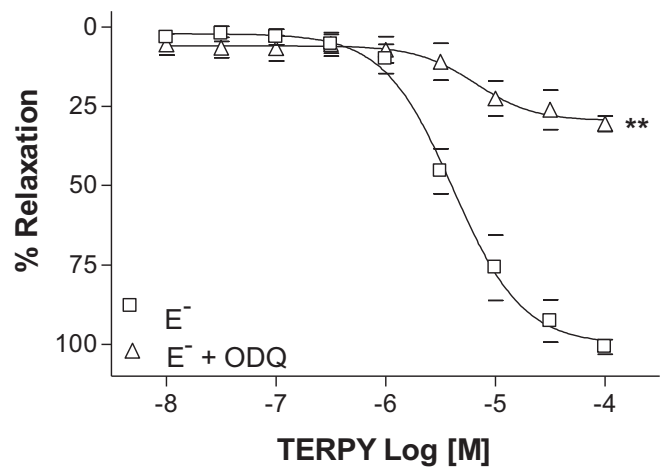

D)

SHR

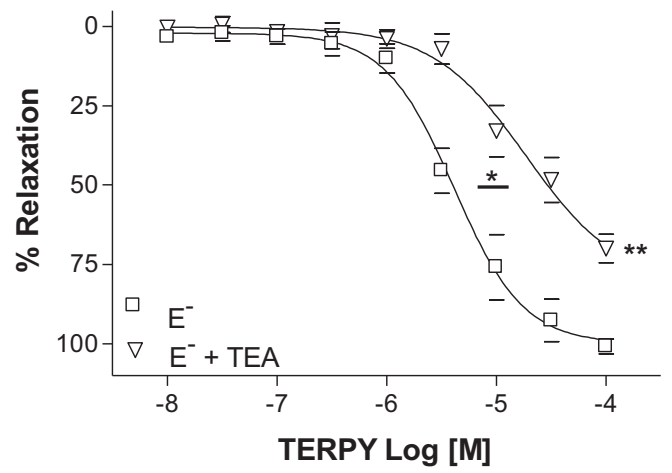

F)

SHR



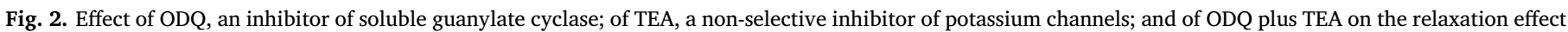

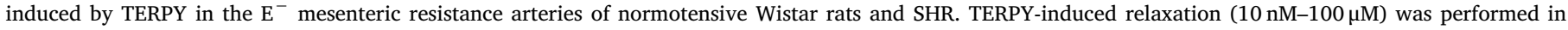

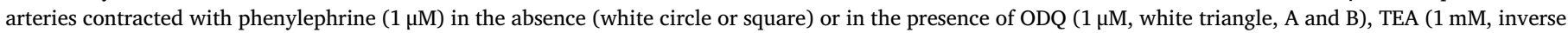

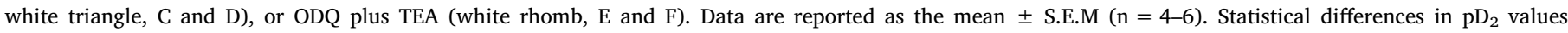
$(* p<0.05)$ and in maximum effect values $(* * p<0.01$ or $* * * p<0.001)$ of concentration-response curves (One-Way ANOVA, followed by Tukey test).

$(0.14 \pm 0.01, \mathrm{n}=4)$ (Fig. $7 \mathrm{~A})$. On the other hand, the stimulation of SHR mesenteric arteries with TERPY $(1 \mu \mathrm{M})$ increased eNOS phosphorylation at $\operatorname{Ser}^{1177}(0.82 \pm 0.09, \mathrm{n}=6$, in arbitrary units $)$ as compared to non-stimulated mesenteric arteries $(0.43 \pm 0.04, n=5)$ (Fig. 7A). In addition, total eNOS expression was increased in SHR mesenteric arteries stimulated with TERPY $(0.57 \pm 0.07, \mathrm{n}=6)$ than in non-stimulated $(0.15 \pm 0.03, \mathrm{n}=6)$. However, in normotensive mesenteric arteries, eNOS expression remained unchanged in non-stimulated $(0.56 \pm 0.09, \mathrm{n}=5)$ or in arteries TERPY-stimulated $(0.46 \pm 0.11, \mathrm{n}=5)$ (Fig. 7B). 




C)
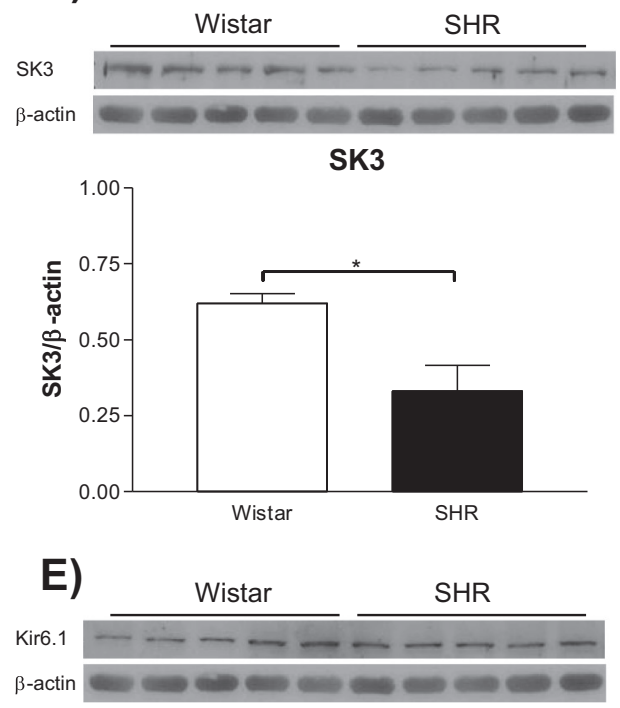

Kir 6.1

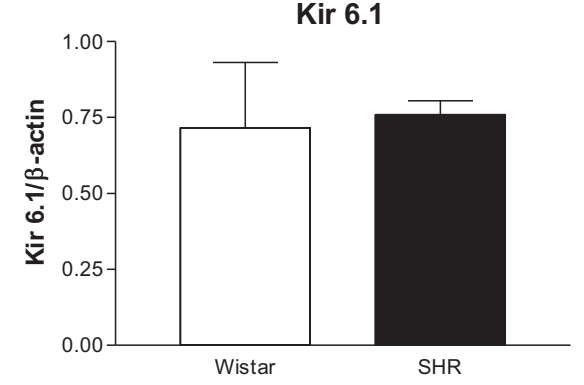



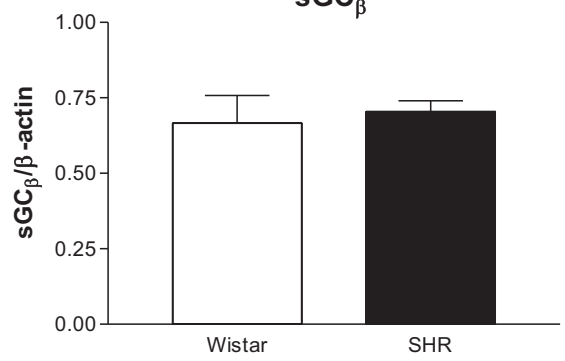

D)


F)

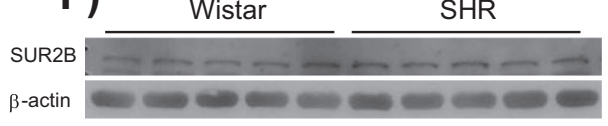

$120 \mathrm{kDa}$

$42 \mathrm{kDa}$
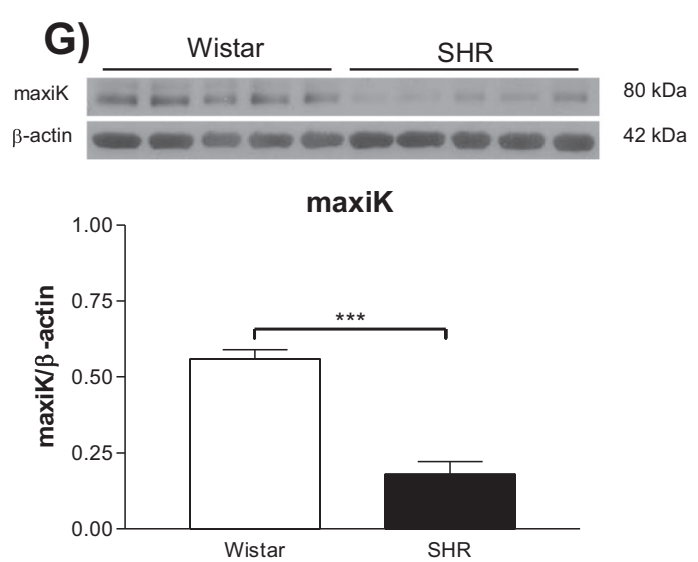


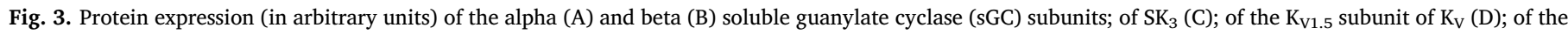

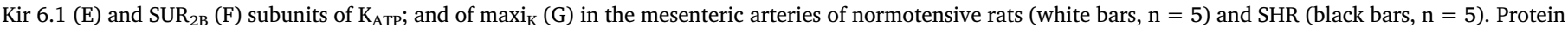

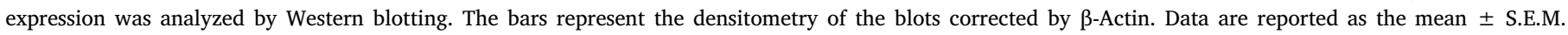
Statistical differences (*p<0.05; ${ }^{* * *} p<0.001$ ) between normotensive Wistar rats and SHR. (One-Way ANOVA, followed by Tukey test).

A)

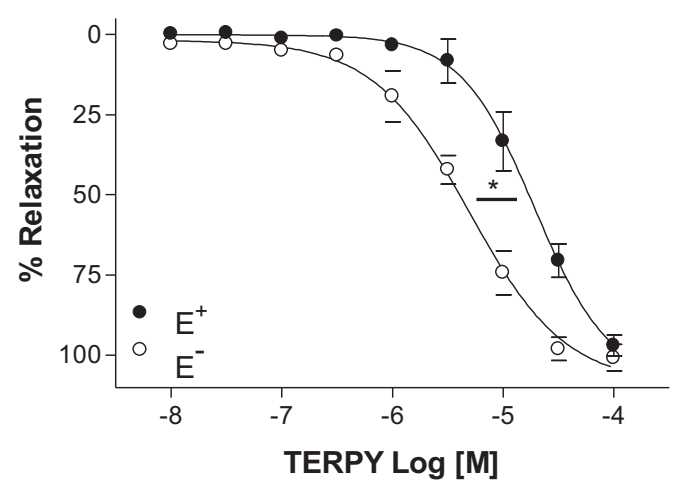

C)

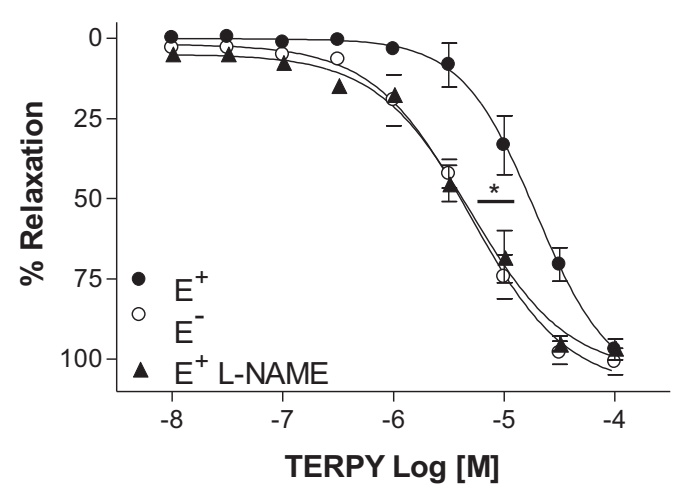

E)

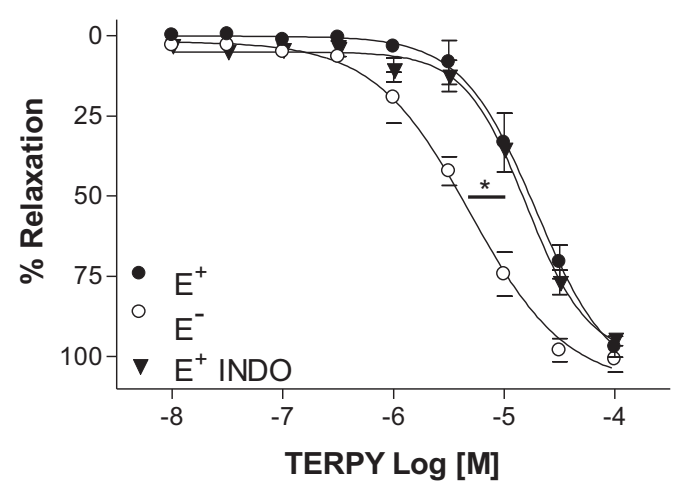

B) SHR

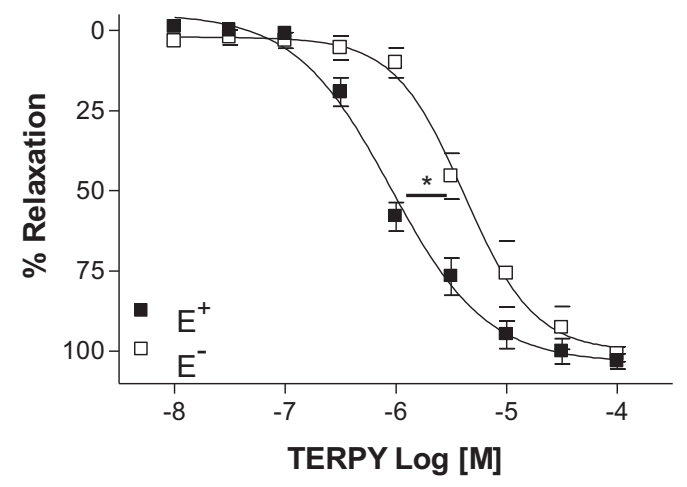

D) SHR

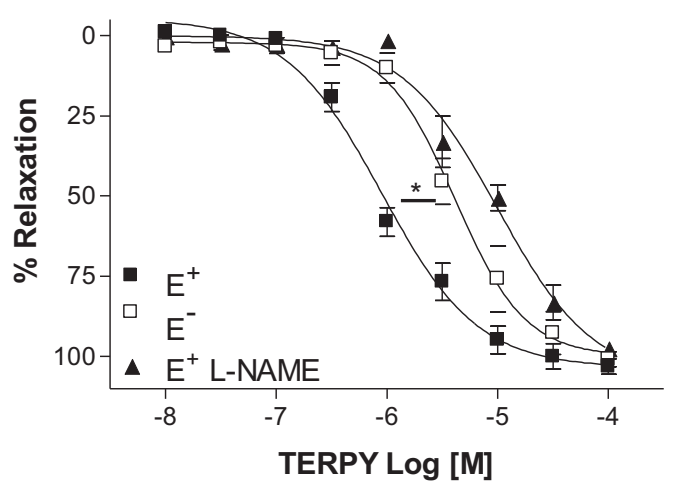

F) SHR

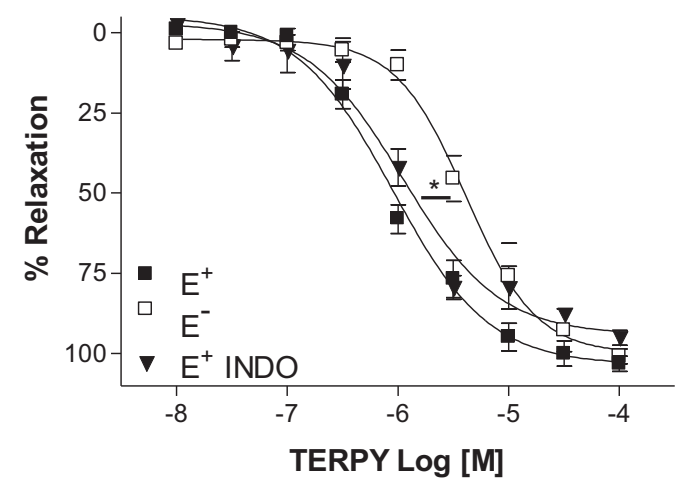

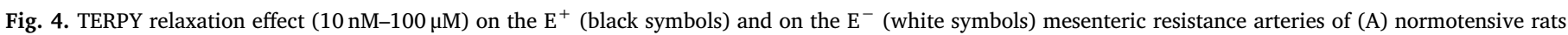

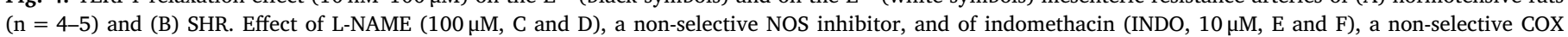

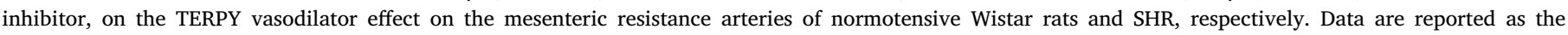
mean \pm S.E.M. Statistical differences in $\mathrm{pD}_{2}$ values $\left({ }^{*} p<0.05\right)$ One-Way ANOVA, followed by Tukey test. 
A)

\section{SHR}



B)

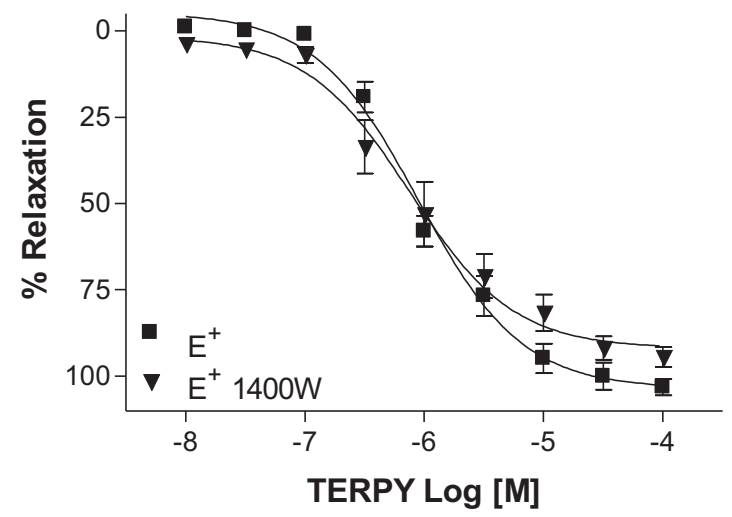

C)

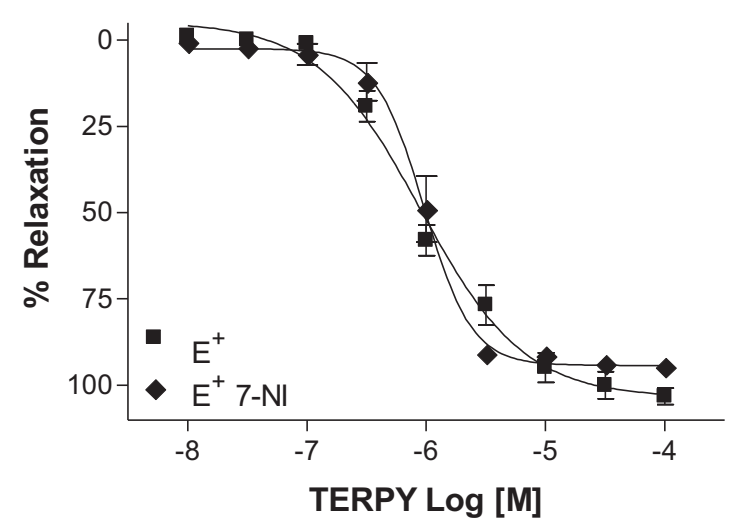

Fig. 5. Cumulative concentration-effect curves $(10 \mathrm{nM}-100 \mu \mathrm{M})$ were constructed for TERPY in the case of $\mathrm{E}^{+}$arteries contracted with phenylephrine $(10 \mu \mathrm{M})$ in the absence (black square, $n=5)$ or in the presence of L-NNA $(100 \mu \mathrm{M}$, black circle, $\mathrm{n}=4$, A), $1400 \mathrm{~W}(10 \mu \mathrm{M}$, inverse black triangle, $\mathrm{n}=4$, B), or 7 -NI $(100 \mu \mathrm{M}$, black rhomb, $n=4, C)$. Data are reported as the mean \pm S.E.M. Statistical differences in $\mathrm{pD}_{2}$ values $\left({ }^{*} p<0.05\right.$, One-Way ANOVA, followed by Tukey test).

3.10. TERPY increases NOx levels and decreases $\mathrm{ONOO}^{-}$production in SHR mesenteric arteries, but not in mesenteric arteries of normotensive rats

In SHR mesenteric arteries, NOx levels was decreased $(0.0034$, $\mathrm{n}=5$ ) compared to mesenteric arteries of normotensive rats $(0.063$,



Fig. 6. Fluorescence intensity (FI) of 4,5-diaminofluorescein diacetate (DAF2DA, $10 \mu \mathrm{M}$ ) in the endothelial cells of the SHR superior mesenteric arteries. FI was evaluated at basal condition (Basal, grey bar) or in the cells incubated with L-NAME $(100 \mu \mathrm{M}$, chess bar). Subsequently, for $10 \mathrm{~min}$, the endothelial cells were stimulated with TERPY $(1 \mu \mathrm{M})$ in the absence (black bar) or in the presence of L-NAME $(100 \mu \mathrm{M}$, bar with horizontal lines), L-NNA $(100 \mu \mathrm{M}$, bar with vertical lines), 7-NI (100 $\mu \mathrm{M}$, dotted lines), 1400W $(10 \mu \mathrm{M}$, bar with diagonal lines), or indomethacin $(10 \mu \mathrm{M}$, bar with checkered lines). Data are reported as the mean \pm S.E.M. $(\mathrm{n}=5)$. ${ }^{*} p<0.05$ represents statistical differences between Basal versus others groups, ${ }^{\dagger} p<0.05$ between L-NAME + TERPY or LNNA + TERPY versus TERPY. (One-Way ANOVA, followed by Tukey test).

$\mathrm{n}=5$ ) (Fig. 7C). On the other hand, $\mathrm{ONOO}^{-}$production, evaluated by 7-CBA, was increased in SHR mesenteric arteries (5711.0 \pm 468.6, $\mathrm{n}=5$ ) than in mesenteric arteries of normotensive rats (3199.0 $\pm 616.8, n=5)$ (Fig. 7D). After TERPY stimulation, NOx levels increased in SHR mesenteric arteries $(0.05, n=5)$, but not in normotensive mesenteric arteries $(0.01, \mathrm{n}=5$ ) (Fig. 7C). ONOO-production was increased in normotensive rats mesenteric arteries $(7150.0 \pm 353.5, \mathrm{n}=5)$, but remained unchanged in SHR mesenteric arteries $(4785.0 \pm 333.2, \mathrm{n}=5)$ (Fig. 7D).

\section{Discussion}

Nitrosyl ruthenium complex TERPY, which is a NO donor, induces concentration-dependent relaxation in $\mathrm{E}^{+}$and $\mathrm{E}^{-}$rings of the second and third branch of mesenteric arteries of normotensive rats and SHR contracted with phenylephrine. Moreover, endothelium exerts distinct modulatory effects on mesenteric artery vascular smooth muscle cells of normotensive rats and SHR. One of the major findings of the present study is that endothelium improves TERPY-induced relaxation in SHR $\mathrm{E}^{+}$mesenteric rings as compared to the corresponding $\mathrm{E}^{-}$rings (Fig. 4A). In contrast, in normotensive rats, endothelium impairs TERPY-induced relaxation potency in $\mathrm{E}^{+}$mesenteric rings as compared to the corresponding $\mathrm{E}^{-}$rings (Fig. 4B).

A previous study has shown that $\mathrm{E}^{-}$aortic and mesenteric segments of hypertensive rats do not present attenuated relaxation in response to the classic nitrovasodilator SNP [33]. Here, we demonstrate that TERPY-induced vasodilation is similar in $\mathrm{E}^{-}$mesenteric arteries of normotensive rats and SHR (Fig. 1), which has also been previously observed in denuded aortas of normotensive rats and SHR [8]. Another study has verified that denuded resistance vessels of $2 \mathrm{~K}-1 \mathrm{C}$ and $2 \mathrm{~K}$ rats do not differ in terms of TERPY-induced vasodilator effect [20]. Therefore, the total functional capacity of vascular smooth muscle to relax in response to compounds that release NO does not seem to change with hypertension [33].

sGC is a heterodimeric protein composed of two subunits, alpha ( $\alpha$ ) 
A)
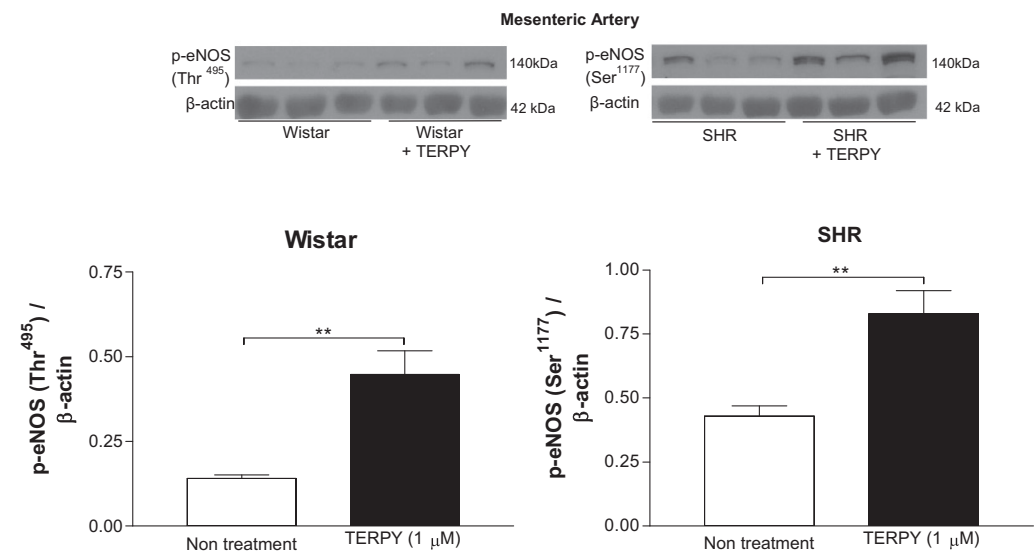

C)

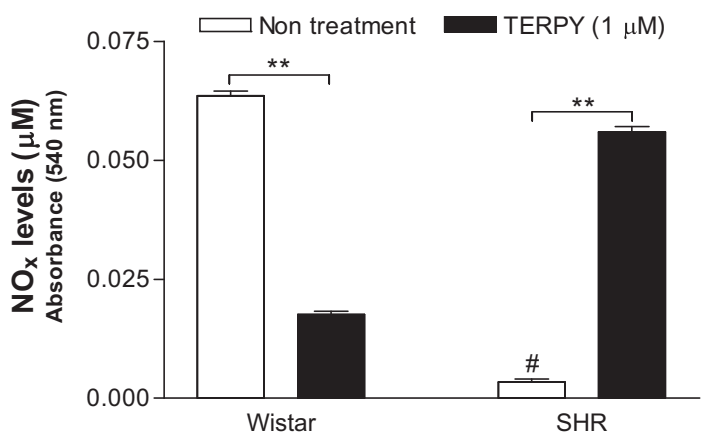

B)
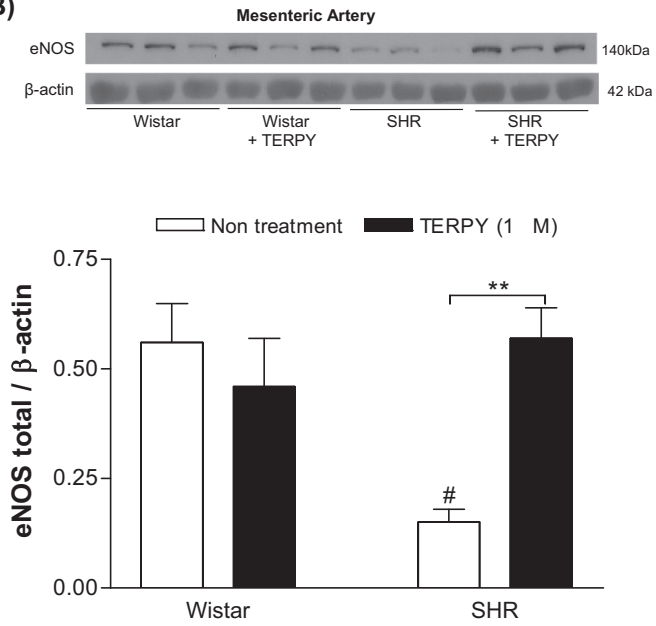

D)

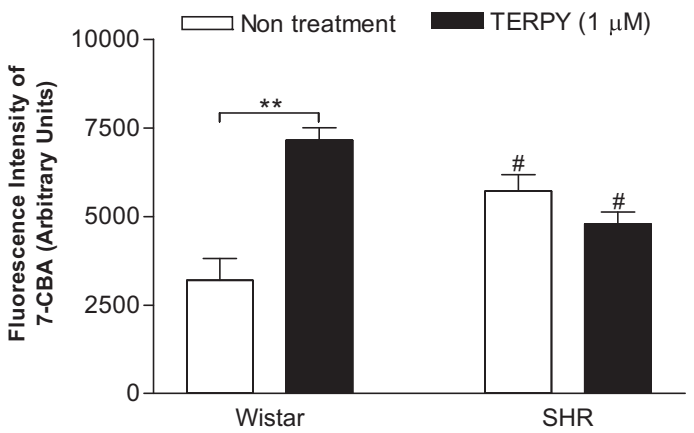

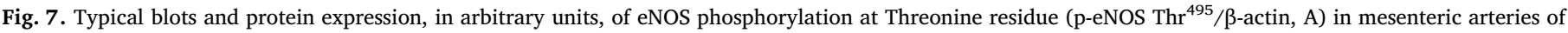

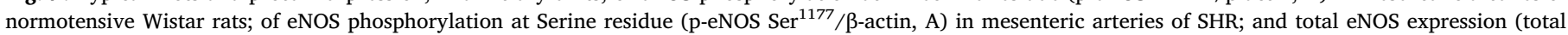

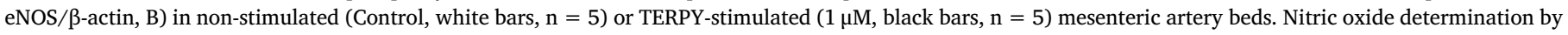

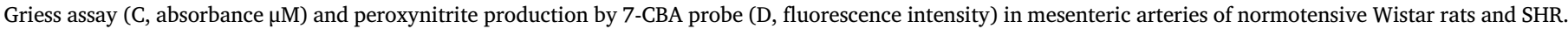

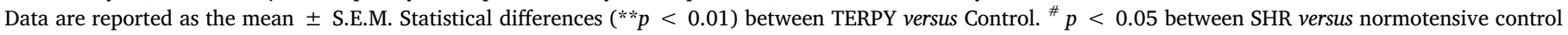
group (One-Way ANOVA, followed by Tukey test).

and beta ( $\beta$ ), and a prosthetic heme group. NO binds to the sGC heme domain in vascular smooth muscle cells, to activate sGC and to raise cyclic 3',5'-guanosine monophosphate (cGMP) concentration. cGMP effects are mediated by cGMP-dependent protein kinase $\mathrm{G}[34,35]$, which can activate sarco-endoplasmic reticulum $\mathrm{Ca}^{2+}$-ATPase (SERCA) [36] and potassium channels [37] as well as inhibit inositol tris-phosphate $\left(\mathrm{IP}_{3}\right)$-mediated $\mathrm{Ca}^{2+}$-release [38]. All these actions reduce cytosolic calcium concentration in vascular smooth muscle cells, to promote relaxation.

ODQ (a selective sGC inhibitor) or TEA (a non-selective potassium channel blocker) diminished the maximum vasodilator effect induced by TERPY with similar amplitude in $\mathrm{E}^{-}$mesenteric artery rings of normotensive rats and SHR, but neither ODQ nor TEA abolishes relaxation (Fig. 2A-D). However, in combination, ODQ and TEA abolish TERPY-induced relaxation (Fig. $2 \mathrm{E}$ and F). These results suggest that the final TERPY-stimulated relaxation pathway in the vascular smooth muscle of normotensive rats and SHR mesenteric rings involves sGC and potassium-channel activation.

Resistance vessels of normotensive rats and SHR have similar SGC expression of $\alpha$ and $\beta$ subunits (Fig. 3A and B). Our data corroborate with the results of Ndisang and cols. [39], who have shown that sGC expression remains unaltered in vascular smooth muscle cells of SHR and Wistar-Kyoto rats of the same age. These results clarify the similar amplitude of TERPY-induced relaxation in $\mathrm{E}^{-}$mesenteric arteries of normotensive rats and SHR in the presence of ODQ.
Vascular smooth muscle cells and endothelial cells that form walls in microcirculation vessels express an array of potassium channels that play an important role in microcirculation modulation in both healthy and diseased vessels. Mesenteric beds express at least four different classes of potassium channels, including inward-rectifier $\mathrm{K}^{+}$channels (Kir), ATP-sensitive $\mathrm{K}^{+}$channels $\left(\mathrm{K}_{\mathrm{ATP}}\right)$, voltage-gated $\mathrm{K}^{+}$channels $\left(\mathrm{K}_{\mathrm{V}}\right)$, and conductance calcium-activated $\mathrm{K}^{+}$channels [40]. A previous study has shown that SHR mesenteric vessels have larger calcium-activated potassium and smaller $\mathrm{Kv}$ current components as compared to WKY, which suggests that these differences contribute to eliciting the distinct TEA effect, resting membrane potential, $\mathrm{Ca}^{2+}$ influx, and $\mathrm{K}_{\mathrm{Ca}}$ current reported in hypertensive arteries [41]. Here, we demonstrate that SHR mesenteric beds have lower number of small conductance calcium-activated potassium channels (SK3) (Fig. 3C) and big conductance calcium-activated potassium channels (maxiK) (Fig. 3G) as compared to normotensive rats. However, in the event of TERPY-induced relaxation, TEA produces similar responses in vessels of normotensive rats and SHR (Fig. 2C and D). This is the reason why we have not tested more selective potassium channel inhibitors. Araújo and cols. [20] have suggested that a compensatory mechanism comes into play to guarantee efficient relaxation even if one channel subtype is impaired. Herein, we have found that mesenteric arteries of normotensive rats and SHR have similar endothelium-independent relaxation (Fig. 1) even though SHR present impaired expression of specific potassium channels (Fig. 3C and G). 
Reduced peripheral vascular resistance could be directly attributed to the TERPY-induced hypotensive action in normotensive rats and SHR $[8,15,17]$. Nevertheless, TERPY promotes a greater hypotensive effect in SHR as compared to normotensive rats $[8,15]$. This fact happens because endothelium significantly enhances TERPY potency in SHR mesenteric arteries (Fig. 4A), whereas the presence of endothelium impairs TERPY potency in mesenteric arteries of normotensive rats (Fig. 4B).

Endothelial modulation of the TERPY vasodilator effect has been demonstrated in aortas of normotensive rats. This modulation involves mechanisms that differ from the mechanisms observed in SHR aortas. Bonaventura and cols. [14] have demonstrated that endothelium disrupts the TERPY vasodilator effect through a NOS-dependent mechanism, which abates TERPY potency in normotensive rat aortas. TERPY addition increases ROS concentration in aortic endothelial cells, but L-NAME can lower ROS levels. Another special feature of TERPY is that it can oxidize tetrahydrobiopterin $\left(\mathrm{BH}_{4}\right)$ to dihydrobiopterin $\left(\mathrm{BH}_{2}\right)$ [14]. $\mathrm{BH}_{4}$ is an essential co-factor for NOS activity and stabilizes the NOS dimer [42]. In the absence of this co-factor, NOS remains uncoupled and generates more superoxide anion $\left(\mathrm{O}_{2}{ }^{-}\right)$than NO [43]. These results suggest that TERPY induces NOS uncoupling in intact aortas of normotensive rats.

On the other hand, endothelium contributes to the TERPY vasodilator response in SHR aortas [15], which also happens in the case of SHR mesenteric arteries (Fig. 4A). Although TERPY oxidizes $\mathrm{BH}_{4}$ to $\mathrm{BH}_{2}$, SHR blood vessels contain lower $\mathrm{BH}_{4}$ levels $[44,45]$. Furthermore, SHR vascular cells have higher ROS concentration, which can be decreased by L-NAME; this suggests that NOS is already uncoupled in SHR $[15,45]$. Hence, TERPY might not promote NOS uncoupling in SHR aortas [15]. In addition, when L-NAME blocks NOS, TERPY potency in SHR aortas [15] and mesenteric arteries (Fig. 4C) diminishes. Besides that, L-NAME reduces the TERPY-induced rise in DAF-2DA fluorescence intensity in SHR mesenteric endothelial cells (Fig. 6). These results point out that NOS activity and NO production in SHR mesenteric resistance arteries intensify the TERPY vasodilator effect.

SHR blood vessels present endothelial dysfunction, which is classically evidenced by impaired endothelium-dependent relaxation, increased ROS levels, decreased NO concentration in endothelial cells, and higher COX-dependent contracting factor production [22,23,46]. We have used indomethacin to evaluate the COX pathway participation in the TERPY vasodilator effect. Interestingly, COX inhibition with indomethacin does not modify TERPY response in mesenteric arteries of normotensive rats or SHR (Fig. $4 \mathrm{E}$ and $\mathrm{F}$ ). These results suggest that cyclooxygenase products do not modulate the TERPY vasodilator effect.

NOS does not play a part in the TERPY vasodilator action in mesenteric arteries of normotensive rats (Fig. 4D). Therefore, we have attempted to identify which NOS specific isoform is involved in TERPYinduced relaxation in SHR mesenteric arteries. Selective nNOS (7-NI) and iNOS (1400W) inhibitors do not affect TERPY-induced relaxation (Fig. 5B and C), but L-NNA, a more selective eNOS inhibitor (Fig. 5A), diminishes TERPY potency. Moreover, TERPY increases DAF-2DA fluorescence intensity, suggesting that TERPY stimulates a rise in NO concentration in SHR endothelial cells. This effect decreases in the presence of L-NNA and L-NAME, but not in the presence of 7-NI, 1400W, or indomethacin (Fig. 6). Hence, eNOS contributes to the TERPY vasodilator effect in SHR mesenteric resistance arteries.

In response to various forms of cellular stimulation, serine residue phosphorylation (Ser ${ }^{635}$ and Ser ${ }^{1179}$ in bovine; Ser ${ }^{633}$ and Ser ${ }^{1177}$ in human) can activate eNOS, to produce NO [47-50]. On the other hand, it is commonly accepted that eNOS activity and NO production is inhibited by phosphorylation at $\mathrm{Thr}^{495}$ and $\mathrm{Thr}^{497}$ [49,51-53]. We have observed that TERPY elicits eNOS Ser ${ }^{1177}$ phosphorylation in $\mathrm{E}^{+}$mesenteric arteries of SHR (Fig. 7A). This response agrees with the increasing at NOx levels (Fig. $7 \mathrm{C}$ ) and decreases at $\mathrm{ONOO}^{-}$production (Fig. 7D). Recently, by using human umbilical vein endothelial cells (HUVEC), we have demonstrated that TERPY promotes eNOS hyperactivation and eNOS phosphorylation at Ser ${ }^{1177}$ [54]. In addition, TERPY increased eNOS expression only in mesenteric arteries of SHR (Fig. 7B), which may contribute to increased levels of NO. However, in $\mathrm{E}^{+}$mesenteric arteries of Wistar rats, eNOS phosphorylation at $\mathrm{Thr}^{495}$ was stimulated by TERPY (Fig. 7A), simultaneously there was a decrease in NOx levels (Fig. 7C). eNOS phosphorylation at $\mathrm{Thr}^{495}$ was related with ROS formation [52,55], which explains the increase of $\mathrm{ONOO}^{-}$production in $\mathrm{E}^{+}$mesenteric arteries of normotensive rats stimulated with TERPY (Fig. 7D).

Taken together, our data suggest that TERPY promotes relaxation in $\mathrm{E}^{+}$and $\mathrm{E}^{-}$mesenteric arteries of normotensive rats and SHR. TERPYinduced vascular relaxation involves activation of sGC and of potassium channels sensitive to TEA in $\mathrm{E}^{-}$mesenteric arteries of normotensive and SHR rats. Furthermore, endothelium modulates the TERPY-induced vasodilator action in mesenteric arteries of normotensive rats and SHR in different ways. On the one hand, NOS inhibition with L-NAME increases TERPY potency in normotensive rats, once TERPY promotes eNOS $\mathrm{Thr}^{495}$ phosphorylation in Wistar $\mathrm{E}^{+}$mesenteric arteries; on the other hand, L-NAME lowers TERPY potency in SHR. In this way, endothelium and notably NOS contributes to the TERPY vasodilator effect in SHR because TERPY promotes eNOS Ser ${ }^{1177}$ phosphorylation in SHR $\mathrm{E}^{+}$mesenteric arteries.

Further studies are necessary to find out whether TERPY can outweigh the existing NO donors, like GNT and SNP. Nonetheless, TERPY prompts a slow and long-lasting hypotensive action without eliciting reflex tachycardia [8]. In addition, it does not cause headache or promote cytotoxicity [18]. Moreover, TERPY induces vasodilation in conductance and resistance arteries of normotensive rats and SHR with similar efficacy. In conclusion, TERPY represents a novel and attractive pharmacological tool to study and to understand the NO mechanism of action in experimental hypertension and endothelial dysfunction models: TERPY induces relaxation in blood vessels of SHR, in which, despite endothelial dysfunction, the endothelium and eNOS improve the effect of TERPY.

Supplementary data to this article can be found online at https:// doi.org/10.1016/j.lfs.2018.03.055.

\section{Acknowledgments}

The authors thank Dr. S. H. P. de Oliveira (UNESP, School of Dentistry, Araçatuba) for the use of her research lab.

\section{Author contributions}

- Conceived and designed the experiments: SRP, LMB, CA.

- Synthesized the compound: RSS

- Performed the experiments: SRP, JAT, MDG, MEG.

- Analyzed the data: SRP, MDG, CA.

- Provided the drugs: LMB, CA.

- Contributed to manuscript drafting: SRP, JAT, MEG, LMB, CA.

\section{Conflict of interest}

The authors have no conflicts of interest to declare.

\section{Funding source}

This work was supported by Coordenação de Aperfeiçoamento de Pessoal de Nível Superior (CAPES); Fundação de Amparo à Pesquisa do Estado de São Paulo (FAPESP) [Grant 2011/20998-0, 2012/20398-6, 2015/17080-2]; and Conselho Nacional de Desenvolvimento Científico e Tecnológico (CNPq) [Grant 141323/2013-2]. Financial support of this study did not involve data collection, analysis, and interpretation; manuscript drafting; and decision to submit the article for publication. 


\section{References}

[1] J.G. Umans, R. Levi, Nitric oxide in the regulation of blood flow and arterial pressure, Annu. Rev. Physiol. 57 (1995) 771-790.

[2] Q. Li, J.Y. Yon, H. Cai, Mechanisms and consequences of eNOS dysfunction in hypertension, J. Hypertens. 33 (2015) 1128-1136.

[3] N.D. Vaziri, K. Liang, Y. Ding, Increased nitric oxide inactivation by reactive oxygen species in lead-induced hypertension, Kidney Int. 56 (1999) 1492-1498.

[4] J. Varon, P.E. Marik, Clinical review: the management of hypertensive crises, Crit. Care 7 (2003) 374-384.

[5] J. Abrams, Transdermal nitroglycerin in angina pectoris, Eur. Heart J. 10 (1989) $11-19$.

[6] Publication Committee for the VMAC Investigators (Vasodilatation in the Management of Acute CHF), Intravenous nesiritide vs nitroglycerin for treatment of decompensated congestive heart failure: a randomized controlled trial, JAMA 287 (2002) 1531-1540.

[7] G.S. Francis, Vasodilators in the intensive care unit, Am. Heart J. 121 (1991) $1875-1878$.

[8] F.C. Munhoz, S.R. Potje, A.C. Pereira, M.G. Daruge, R.S. da Silva, L.M. Bendhack, C. Antoniali, Hypotensive and vasorelaxing effects of the new NO-donor [Ru(terpy) (bdq)NO](3+) in spontaneously hypertensive rats, Nitric Oxide 26 (2012) 111-117.

[9] D. Hottinger, D.S. Beebe, T. Kozhimannil, R.C. Prielipp, K.G. Belani, Sodium nitroprusside in 2014: a clinical concepts review, J. Anaesthesiol. Clin. Pharmacol. 30 (2014) 462-471.

[10] M. Feelish, M. Kelm, Biotransformation of organic nitrates to nitric oxide by vascular smooth muscle and endothelial cells, Biochem. Biophys. Res. Commun. 180 (1991) 286-293.

[11] D. Bonaventura, F.S. Oliveira, V. Togniolo, A.C. Tedesco, R.S. da Silva, L.M. Bendhack, A macrocyclic nitrosyl ruthenium complex is a NO donor that induces rat aorta relaxation, Nitric Oxide 10 (2004) 83-91.

[12] C.M. de Gaitani, M.C. de Melo, C.N. Lunardi, F.S. Oliveira, R.S. da Silva, L.M. Bendhack, Hypotensive effect of the nitrosyl ruthenium complex nitric oxide donor in renal hypertensive rats, Nitric Oxide 20 (2009) 195-199.

[13] A.C. Pereira, P.C. Ford, R.S. da Silva, L.M. Bendhack, Ruthenium-nitrite complex as pro-drug releases NO in a tissue and enzyme-dependent way, Nitric Oxide 31 (2011) 192-198.

[14] D. Bonaventura, C.N. Lunardi, G.J. Rodrigues, M.A. Neto, J.A. Vercesi MA, R.G. de Lima, R.S. da Silva, L.M. Bendhack, Endothelium negatively modulates the vascular relaxation induced by nitric oxide donor, due to uncoupling NO synthase, J. Inorg. Biochem. 103 (2009) 1366-1374.

[15] S.R. Potje, F.C. Munhoz, L.A. Perassa, M.E. Graton, A.A. Pereira, A.C. Nakamune, R.S. da Silva, L.M. Bendhack, D.H. Sumida, C. Antoniali, Mechanisms underlying the hypotensive and vasodilator effects of [Ru(terpy)(bdq)NO] + , a nitric oxide donor, differ between normotensive and spontaneously hypertensive rats, Eur. J. Pharmacol. 15 (2014) 222-229.

[16] C.N. Lunardi, R.S. da Silva, L.M. Bendhack, New nitric oxide donors based on ruthenium complexes, Braz. J. Med. Biol. Res. 42 (2009) 87-93.

[17] G.J. Rodrigues, A.C. Pereira, J.A. Vercesi, R.G. de Lima, R.S. da Silva, L.M Bendhack RS, Long-lasting hypotensive effect in renal hypertensive rats induced by nitric oxide released from a ruthenium complex, J. Cardiovasc. Pharmacol. 60 (2012) 193-198.

[18] M. Paulo, G.J. Rodrigues, R.S. da Silva, L.M. Bendhack, A new NO donor failed to release NO and to induce relaxation in the rat basilar arteries, Eur. J. Pharm. Sci. 45 (2012) 344-350.

[19] C. Anile, F. Zanghi, A. Bracali, G. Maira, G.F. Rossi, Sodium nitroprusside and in tracranial pressure, Acta Neurochir. 58 (1981) 203-211.

[20] A.V. Araújo, A.C. Pereira, M.D. Grando, R.S. da Silva, L.M. Bendhack, The new NO donor Terpy induces similar relaxation in mesenteric arteries of renal hypertensive and normotensive rats, Nitric Oxide 35 (2013) 47-53.

[21] J.B. Furness, J.M. Marshall, Correlation of the directly observed responses of mesenteric vessels of the rat to nerve stimulation and noradrenaline with the distribution of adrenergic nerves, J. Physiol. 239 (1974) 75-88.

[22] D. Fu-Xiang, M. Jameson, J. Skopec, A. Diederich, D. Diederich, Endothelial dysfunction of resistance arteries of spontaneously hypertensive rats, J. Cardiovasc. Pharmacol. 20 (1992) S190-S192.

[23] H. Takase, Y. Dohi, M. Kojima, K. Sato, Changes in the endothelial cyclooxygenase pathway in resistance arteries of spontaneously hypertensive rats, J. Cardiovasc. Pharmacol. 23 (1944) 326-330.

[24] M.J. Mulvany, W. Halpern, Contractile properties of small arterial resistance vessels in spontaneously hypertensive and normotensive rats, Circ. Res. 41 (1977) 19-26.

[25] T.W. Kurtz, R.C. Morris Jr, Biological variability in Wistar-Kyoto rats. Implications for research with the spontaneously hypertensive rat, Hypertension 10 (1987) $127-131$.

[26] W.J. Louis, L.G. Howes, Genealogy of the spontaneously hypertensive rat and Wistar-Kyoto rat strains: implications for studies of inherited hypertension, J. Cardiovasc. Pharmacol. 16 (1990) S1-S5.

[27] E.A. Aiello, M.C. Villa-Abrille, E.M. Escudero, E.L. Portiansky, N.G. Pérez, M.C. de Hurtado, H.E. Cingolani, Myocardial hypertrophy of normotensive Wistar-Kyoto rats, Am. J. Physiol. Heart Circ. Physiol. 286 (2004) H1229-1235.

[28] D. Bonaventura, C.N. Lunardi, G.J. Rodrigues, M.A. Neto, L.M. Bendhack, A novel mechanism of vascular relaxation induced by sodium nitroprusside in the isolated rat aorta, Nitric Oxide 18 (2008) 287-295.

[29] N.V. de Cunha, P. Pinge-Filho, C. Panis, B.R. Silva, L. Pernomian, M.D. Grando, R. Cecchini, L.M. Bendhack, M.C. Martins-Pinge, Decreased endothelial nitric oxide, systemic oxidative stress, and increased sympathetic modulation contribute to hypertension in obese rats, Am. J. Physiol. Heart Circ. Physiol. 15 (2014)
H1472-H1480

[30] O.H. Lowry, N.J. Roserbrough, A.L. Farr, R.J. Randall, Protein measurement with the Folin phenol reagent, J. Biol. Chem. 193 (1951) 265-275.

[31] J. Zielonka, A. Sikora, J. Joseph, B. Kalyanaraman, Peroxynitrite is the major species formed from different flux ratios of co-generated nitric oxide and superoxide: direct reaction with boronate-based fluorescent probe, J. Biol. Chem. 285 (2010) $14210-14216$.

[32] R.G. de Lima, M.G. Sauaia, D. Bonaventura, A.C. Tedesco, L.M. Bendhack, R.S. da Silva, Influence of ancillary ligand $\mathrm{L}$ in the nitric oxide photo-release by the $[\mathrm{Ru}(\mathrm{L})$ (terpy)NO $]^{3+}$ complex and its vasodilator activity based on visible light irradiation, Inorg. Chim. Acta 359 (2006) 2543-2549.

[33] Y. Shirasaki, C. Su, T.J. Lee, P. Kolm, W.H. Cline, G.A. Nickols, Endothelial modulation of vascular relaxation to nitrovasodilators in aging and hypertension, J. Pharmacol. Exp. Ther. 239 (1986) 861-866.

[34] M. Feelisch, E.A. Noack, Correlation between nitric oxide formation during degradation of organic nitrates and activation of guanylate cyclase, Eur. J. Pharmacol. 139 (1987) 19-30.

[35] E. Martin, K. Davis, K. Bian, Y.C. Lee, F. Murad, Cellular signaling with nitric oxide and cyclic guanosine monophosphate, Semin. Perinatol. 24 (2000) 2-6.

[36] H.K. Simmerman, L.R. Jones, Phospholamban: protein structure, mechanism of action, and role in cardiac function, Physiol. Rev. 78 (1998) 921-947.

[37] M. Sausbier, R. Schubert, V. Voigt, C. Hirneiss, A. Pfeifer, M. Korth, T. Kleppisch, P. Ruth, F. Hofmann, Mechanisms of NO/cGMP-dependent vasorelaxation, Circ. Res. 87 (2000) 825-830.

[38] J. Schlossmann, A. Ammendola, K. Ashman, X. Zong, A. Huber, G. Neubauer, G.K. Wang, H.D. Allescher, M. Korth, M. Wilm, F. Hofmann, P. Ruth, Regulation of intracellular calcium by a signaling complex of IRAG, IP $_{3}$ receptor and cGMP kinase Ibeta, Nature 404 (2000) 197-201.

[39] J.F. Ndisang, W. Zhao, R. Wang, Selective regulation of blood pressure by heme oxygenase-1 in hypertension, Hypertension 315 (2002) 315-321.

[40] W.F. Jackson, Potassium channels in the peripheral microcirculation, Microcirculation 12 (2005) 113-127.

[41] R.H. Cox, I. Lozinskaya, N.J. Dietz, Differences in K+ current components in mesenteric artery myocytes from WKY and SHR, Am. J. Hypertens. 14 (2001) 897-907.

[42] N.J. Alp, K.M. Channon, Regulation of endothelial nitric oxide synthase by tetrahydrobiopterin in vascular disease, Arterioscler. Thromb. Vasc. Biol. 24 (2004) 413-420.

[43] A.C. Montezano, R.M. Touyz, Reactive oxygen species and endothelial function-role of nitric oxide synthase uncoupling and Nox family nicotinamide adenine dinucleotide phosphate oxidases, Basic Clin. Pharmacol. Toxicol. 110 (2012) 87-94.

[44] H.J. Hong, G. Hsiao, T.H. Cheng, M.H. Yen, Supplemention with tetrahydrobiopterin suppresses the development of hypertension in spontaneously hypertensive rats, Hypertension 38 (2001) 1044-1048.

[45] H. Li, K. Witte, M. August, I. Brausch, U. Gödtel-Armbrust, A. Habermeier, E.I. Closs, M. Oelze, T. Münzel, U. Förstermann, Reversal of endothelial nitric oxide synthase uncoupling and up-regulation of endothelial nitric oxide synthase expression lowers blood pressure in hypertensive rats, J. Am. Coll. Cardiol. 47 (2006) 2536-2544.

[46] K. Fujii, M. Tominaga, S. Ohmori, K. Kobayashi, T. Koga, Y. Takata, M. Fujishima, Decreased endothelium-dependent hyperpolarization to acetylcholine in smooth muscle of the mesenteric arteries of spontaneously hypertensive rats, Circ. Res. 70 (1992) 660-669.

[47] S. Dimmeler, I. Fleming, B. Fisslthaler, C. Hermann, R. Busse, A.M. Zeiher, Activation of nitric oxide synthase in endothelial cells by Akt-dependent phosphorylation, Nature 399 (1999) 601-605.

[48] M.B. Harris, H. Ju, V.J. Venema, H. Liang, R. Zou, B.J. Michell, Z.P. Chen, B.E. Kemp, R.C. Venema, Reciprocal phosphorylation and regulation of endothelial nitric-oxide synthase in response to bradykinin stimulation, J. Biol. Chem. 276 (1999) 16587-16591.

[49] I. Fleming, B. Fisslthaler, S. Dimmeler, B.E. Kemp, R. Busse, Phosphorylation of Thr (495) regulates $\mathrm{Ca}(2+)$ /calmodulin-dependent endothelial nitric oxide synthase activity, Circ. Res. 88 (2001) E68-75.

[50] B.J. Michell, M.B. Harris, Z.P. Chen, H. Ju, V.J. Venema, M.A. Blackstone, W. Huang, R.C. Venema, B.E. Kemp, Identification of regulatory sites of phosphorylation of the bovine endothelial nitric-oxide synthase at serine 617 and serine 635, J. Biol. Chem. 277 (2002) 42344-42351.

[51] B.J. Michell, Z. Chen, T. Tiganis, D. Stapleton, F. Katsis, D.A. Power, A.T. Sim, B.E. Kemp, Coordinated control of endothelial nitric-oxide synthase phosphorylation by protein kinase C and the cAMP-dependent protein kinase, J. Biol. Chem. 25 (2001) 17625-17628

[52] M.I. Lin, D. Fulton, R. Babbitt, I. Fleming, R. Busse, K.A. Pritchard, W.C. Sessa, Phosphorylation of threonine 497 in endothelial nitric-oxide synthase coordinates the coupling of L-arginine metabolism to efficient nitric oxide production, J. Biol. Chem. 278 (2003) 44719-44726.

[53] C.A. Chen, L.J. Druhan CA, S. Varadharaj, Y.R. Chen, J.L. Zweier, Phosphorylation of endothelial nitric-oxide synthase regulates superoxide generation from the enzyme, J. Biol. Chem. 283 (2008) 27038-27047.

[54] S.R. Potje, Z. Chen, S.D.S. Oliveira, L.M. Bendhack, R.S. da Silva, M.G. Bonini, C. Antoniali, R.D. Minshall, Nitric oxide donor $[\mathrm{Ru}(\mathrm{terpy})(\mathrm{bdq}) \mathrm{NO}]^{3+}$ induces uncoupling and phosphorylation of endothelial nitric oxide synthase promoting oxidant production, Free Radic. Biol. Med. 112 (2017) 587-596.

[55] T.J. Guterbaum, T.H. Braunstein, A. Fossum, N.H. Holstein-Rathlou, C.T. TorpPedersen, H. Domínguez, Endothelial nitric oxide synthase phosphorylation at Threonine 495 and mitochondrial reactive oxygen species formation in response to a high $\mathrm{H}_{2} \mathrm{O}_{2}$ concentration, J. Vasc. Res. 50 (2013) 410-420. 